\title{
HISTOTOPOGRAPHIC AND MORPHOMETRIC CHARACTERISTICS OF THE ORAL MUCOSA POSTOPERATIVE WOUNDS HEALING, DEPENDING ON THE METHOD OF CONNECTING THE WOUND EDGES
}

\author{
Oleksiy Pavlenko \\ Department of Dentistry ${ }^{l}$ \\ institut_stomat@ukr.net \\ Mikola Boiko \\ Department of Dentistry ${ }^{l}$ \\ mikola.boiko.stom@gmail.com \\ Irina Savitskaya \\ Department of Experimental Surgery ${ }^{2}$ \\ irinasavitska@ukr.net \\ Olga Geylenko \\ Department of Experimental Surgery ${ }^{2}$ \\ ogeylenko@ukr.net \\ ${ }^{1}$ Shupyk National Healthcare University of Ukraine \\ 9 Dorohozhytska str.,Kyiv, Ukraine, 04112 \\ ${ }^{2}$ Shalimov National Institute of Surgery and Transplantology \\ National Academy of Medical Sciences of Ukraine \\ 30 Heroyv Sevastopolya str., Kyiv, Ukraine, 03680
}

Abstract

Implementation of high-quality tissue connections and hemostasis in oral surgery is an urgent problem of modern dentistry, due to the lack of available universal methods that would help to facilitate the work of oral surgeon and reduce wound healing time.

The aim of the research. To investigate and study the regeneration processes in the oral mucosa after high-frequency electric welding, suturing and medical adhesive composition.

Materials and methods. This study compared the effect of three connection methods and hemostasis: high-frequency electric welding (EKVZ-300M1 «PATONMED ${ }^{\circledR} »$, Ukraine), suture method (nylon $5 / 0 《 \operatorname{PIRUS}^{\circledR} »$, China), adhesive composition («Histoacryl ${ }^{\circledR} »$, Germany). 72 rabbits were involved in experiment. An incision of the soft tissues of the vestibulum of the oral cavity of the maxilla with a length of 1.3-1.5 cm was made. On days 3, 7, 14 and 21, tissue samples were excised, histological and morphometric examination of the material were performed.

Results. By statistical data processing of 72 rabbits was found that the reliability of differences in the levels of morphometric parameters between groups on each day is very high, as evidenced by the calculated values of the U-test. In 38 cases $(90.5 \%)$, the significance level was $p \leq 0.01$, in the other 4 cases $-p \leq 0.05$. The lowest value level of neutrophilic granulocytes was in rabbits of group No. 1 (electric welding). In rabbits of group No. 1 GFBC were not observed in the 8 fields of view throughout the experiment.

Conclusions. High-frequency electric welding of soft tissues can be used for effective intraoperative hemostasis and connection of the intraoral wound edges.

Due to the absence of a foreign body (adhesive masses, filaments) and moderate alterative effect, histological examination indicates accelerated activation of regenerative processes in the early stages of observation in rabbits of group No. 1.

Keywords: mucous membrane, oral surgery, high-frequency electric welding, nylon, adhesive composition, experiment, histology, morphometry.

DOI: $10.21303 / 2504-5679.2021 .001845$ 


\section{Introduction}

Active development and improvement of reconstructive surgery of the oral cavity is aimed at increasing the clinical effectiveness of various methods of reconstruction of bone and soft tissue volume of the jaws, in order to expand the indications for orthodontic, orthopedic and implant treatment [1]. Achieving quality, rapid connection and hemostasis of oral tissues are important steps in the performance of any surgery, especially in outpatient settings, and remain relevant to these days $[2,3]$. To solve it, many methods and techniques are proposed, which are constantly modified, new ones appear $[3,4]$. Currently, there are mechanical, chemical, physical, biological and combined methods to stop bleeding [1,2]. Their use should be justified and the least traumatic in each individual case, which will avoid the development of intra - and postoperative complications [5]. In this regard, the use of physical methods in oral surgery is debatable [6, 7]. The team of authors of E. O. Paton EWI of the National Academy of Sciences of Ukraine (Kyiv) developed a fundamentally new method of high-frequency electric welding, which is widely used in the surgical field due to the simultaneous connection of tissues and the implementation of hemostasis [3, 8]. The stage of selection of suture material is one of the most important in surgical treatment, which depends on the course of the postoperative period and the timing of wound healing [4, 9, 10]. There are publications that affect the effect of suture material even on bone tissue [11]. Due to the ambiguous views of specialists and the development of the chemical industry as an alternative to the suture technique, a medical adhesive composition was created, which facilitated the work of surgeons $[12,13]$. However, it is not always possible to connect tissues in anatomical and topographic areas that are prone to dynamic movements $[14,15]$. There are some allergic reactions cases [16-18]. The limit for widespread usage is the high price of fabric adhesive [14].

The purpose of this study - to investigate and study the regeneration processes after high-frequency electric welding (EKVZ-300M1 «PATONMED ${ }^{\circledR} »$, Ukraine), suturing (nylon 5/0 $\left\langle\operatorname{PIRUS}^{\circledR} »\right.$, China) and medical adhesive composition («Histoacryl ${ }^{\circledR} »$, Germany), based on the evaluation of histological material and analysis of morphometric changes in the oral mucosa (OM).

\section{Materials and methods}

Experimental studies were performed from October 2017 to May 2020 in Department of experimental surgery Shalimov National Institute of Surgery and Transplantology National Academy of Medical Sciences of Ukraine on 72 adult, outbred rabbits of different sexes with a body weight of 2260 to $4650 \mathrm{~g}$ (average weight $3565 \pm 100 \mathrm{~g}$ ). All experimental work was performed in compliance with ethical human and animals' treatment in accordance with the provisions of the Council of Europe Convention on Biomedicine. During the experiment, they were guided by the standards of the Guide for the core and Use of Laboratory Animals (National Academy Press, Revised, 1996) and the American Heart Association's «Guidelines for the Use of Animal in Research» [19, 20].

After anesthesia, which was achieved by intraperitoneal injection of $5 \%$ sodium thiopental solution at a rate of $40 \mathrm{mg} / \mathrm{kg}$ body weight and intravenous injection of $1 \%$ propofol solution at a rate of $5 \mathrm{mg} / \mathrm{kg}$ body weight, surgery was performed. During each of the series of operations, the animals were fixed to the operating table, the surface of the oral mucosa was treated with $0.05 \%$ chlorhexidine solution. Local anesthesia was achieved by infiltration of $0.3 \mathrm{ml}$ of $1 \%$ lidocaine.

Incision was made longitudinal wound measuring $1.3-1.5 \mathrm{~cm}$ in length and $0.5-0.7 \mathrm{~cm}$ in depth with a scalpel blade No. 15. The mucous membrane and submucosal base were separated to the periosteum.

Rabbits were randomly divided into 3 groups of 24 rabbits in each group. In group No. 1, connections and hemostasis of tissues were performed using high-frequency electric welding (EKVZ-300M1 «PATONMED ${ }^{\circledR} »$, Ukraine) with adjustment of welding parameters [8]. In group No. 2 by applying three knotted sutures with suture material $5 / 0$ based on nylon («PIRUS ${ }^{\circledR} »$, China). In group No. 3 using an adhesive composition («Histoacryl ${ }^{\circledR} »$, Germany). On days 3, 7, 14, and 21 , the animals were removed from the experiment and tissue samples were excised for histological and morphometric examination. The removed area where the intervention was performed, together with the wound canal and a gap of up to $3 \mathrm{~mm}$, which included intact tissue, was fixed in $10 \%$ neutral formalin solution for 24 hours, dehydrated in ethyl alcohol increasing 
concentrations (from $50^{\circ}$ to $96^{\circ}$ ), clarified in xylene for 30 minutes, kept for two hours at a temperature of $37^{\circ} \mathrm{C}$ in a mixture of xylene and paraffin (1:1) and twice in paraffin for 30 minutes at $56{ }^{\circ} \mathrm{C}$, compacted in paraffin according to conventional methods, made $5 \mu \mathrm{m}$ thick histological sections, which were stained with hematoxylin and eosin, picrofuxin according to van Gizon.

Histological examinations were performed using a Leica DM 500 research optical microscope with a computer annex and the possibility of morphometric studies. Photographing the preparations was performed using a Leica ICC50 HD camera. Morphometric processing was performed using a video analyzer and computer program «Paradise», developed by the research and production company «Eva». The density of neutrophilic granulocytes, lymphocytes, macrophages, giant foreign body cells in 8 fields of view at a magnification of 400 times, then recalculated the content of these cells in $1 \mathrm{~mm}^{2}$ and statistically processed the obtained values between groups (Table 1).

Statistical analysis was performed using the standard software package SPSS 17.0. For each group, the average values of morphometric parameters and their errors $(M \pm m)$ were calculated, and a statistical analysis of the dynamics of changes in the levels of morphometric parameters was performed. The non-parametric Mann-Whitney method was used to assess the reliability and statistical significance of differences in the levels of morphometric parameters determined for each group on each day.

Table 1

The average values of cell density $(1 \mathrm{~mm} 2 / \mathrm{GFBC}$ in the 8 fields of view)

\begin{tabular}{ccccc}
\hline Indicator & Day & Group 1 (EKVZ-300M1) & Group 2 (Nylon 5/0) & Group 3 (Histoacryl) \\
\hline A & 3 & $23.15 \pm 2.08$ & $317.14 \pm 59.13$ & $35.55 \pm 4.04$ \\
A & 7 & $24.09 \pm 1.96$ & $186.71 \pm 29.53$ & $28.15 \pm 1.82$ \\
A & 14 & $17.01 \pm 0.16$ & $94.15 \pm 15.91$ & $24.91 \pm 1.35$ \\
A & 21 & $12.44 \pm 1.07$ & $78.51 \pm 9.64$ & $17.64 \pm 1.82$ \\
B & 3 & $459.17 \pm 43.67$ & $51.55 \pm 7.69$ & $108.50 \pm 1.21$ \\
B & 7 & $215.41 \pm 19.11$ & $82.31 \pm 12.08$ & $86.55 \pm 6.92$ \\
B & 14 & $128.37 \pm 10.15$ & $68.36 \pm 17.04$ & $82.66 \pm 7.83$ \\
B & 21 & $98.16 \pm 1.03$ & $59.37 \pm 10.11$ & $69.17 \pm 5.41$ \\
C & 3 & $7.81 \pm 0.68$ & $8.31 \pm 0.95$ & $3.10 \pm 0.44$ \\
C & 7 & $8.64 \pm 0.89$ & $14.48 \pm 2.63$ & $6.10 \pm 1.2$ \\
C & 14 & $2.05 \pm 0.19$ & $10.46 \pm 6.25$ & $1.30 \pm 0.2$ \\
C & 21 & $1.41 \pm 0.2$ & $4.89 \pm 0.51$ & $1.33 \pm 0.14$ \\
D & 3 & 0 & 0 & 2 \\
D & 7 & 0 & 2 & 1 \\
D & 14 & 0 & 1 & 0 \\
D & 21 & 0 & 1 & 0
\end{tabular}

Note: A - neutrophilic granulocytes; B - lymphocytes; $C$ - macrophages; D-Giant foreign body cells (GFBC); 0 - the indicator of the phenomenon is equal to zero

\section{Research results}

Qualitative results were described according to the method of connection and hemostasis at 3, 7, 14 and 21 days after the intervention.

\section{High-frequency electric welding}

On day $3 \mathrm{rd}$, the wound area was covered with a coagulation layer under which were compacted paranecrotic tissues, the surrounding tissues were infiltrated with lymphocytes, the epithelial plate was absent in a significant area. A small number of fibroblastic cells was observed in the treatment area. Manifestations of stasis and microcirculation disorders were observed. Blood vessels are dilated, swollen, atonic. On day 7 th, the epithelial plate began to regenerate on both sides of the wound and crawl to the wound surface. Coagulation scab was absent on most of the surface, in some areas 
its fragments were observed in the newly formed young granulation tissue lining the treatment area. The own plate of a mucous membrane is condensed due to compression and moderate hypostasis. In the treatment area there were compressed collagen fibers, the intercellular space decreased (Fig. 1).

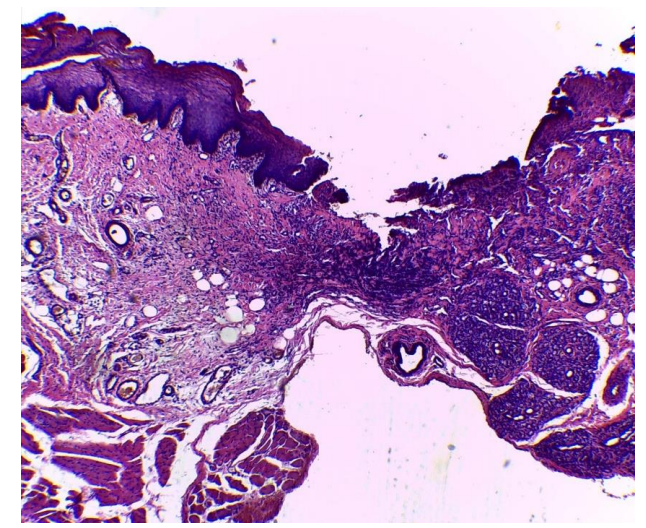

Fig. 1. Rabbit's OM in 7 days after high-frequency electric welding. Hematoxylin and eosin staining. Magnification 100

Signs of inflammation are weak. On the 14th day, the epithelial plate was thinned, partially restored, the own plate was compacted. The process of restructuring of tissue elements was observed. Blood vessels in the surrounding tissue dilated sharply, were full-blooded. Granulation tissue matured, the formation of smoothness of the epithelial-connective tissue border in the healing zone was observed. The collagen fibers of the newly formed connective tissue were located mainly tangentially. Actually, the tissue was moderately mature without any signs of inflammation. On the 21st day, the treatment area is covered with a layer of squamous non-keratinized epithelium with a slight deformation of the epithelial plate. The epithelial plate was completely restored, was thinned in a small area, above the scar it formed deep growths in the newly formed connective tissue, the epithelial-connective tissue border was folded, which is characteristic of intact areas of the mucous membrane of the oral cavity.

\section{Nylon 5/0}

On the 3rd day, a thin layer of granulation tissue is formed under the surface of the wound, it and the surrounding tissues are abundantly infiltrated mainly by neutrophilic granulocytes and lymphocytes, macrophages are solitary. Signs of epithelial plate recovery are weak. Full blood vessels with signs of stasis. On the 7th day, a significant volume of granulation tissue is formed in the area of the suture, neutrophil-lymphocytic infiltration increases closer to the location of the sutures, macrophages are present (Fig. 2).

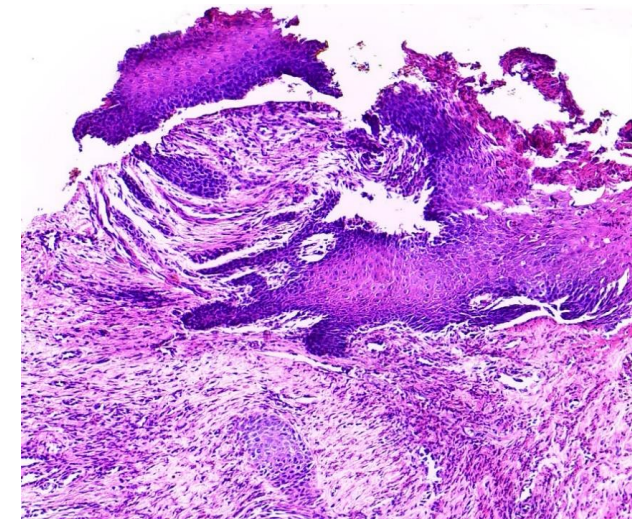

Fig. 2. Rabbit's OM in 7 days after suturing on the basis of nylon 5/0. Hematoxylin and eosin staining. Magnification 100 
The epithelial plate is partially restored. On the 14th day, the channels of the filaments, located in the thickness of the newly formed connective tissue are visible, along which the connective tissue capsule is observed. The epithelial plate is not completely restored, epithelial cells crawl to the edges of the wound, but complete epithelialization is not observed. Single giant foreign body cells. Moderate leukocyte-lymphocyte infiltration of the scar zone on the surrounding tissues. On the 21st day, the epithelial plate was restored, in different areas of uneven thickness, mostly thickened relative to intact areas, the basal layer formed outgrowths in the newly formed connective tissue of the suture area. The newly formed connective tissue is compacted. Small clusters of lymphocytes and macrophages were observed in the connective tissue around the filaments.

\section{N-butyl-2-cyanoacrylate adhesive composition}

On the 3rd day in the area of the adhesive masses there were moderate signs of inflammation, the adhesive masses were surrounded by a thin layer of newly formed tissue, which consisted of 2-3 rows of fibroblasts and thin bundles of collagen fibers. The surrounding tissue was moderately infiltrated mainly by lymphocytes and neutrophilic granulocytes, single macrophages and giant foreign body cells. The epithelial plate was not restored. Blood vessels are full-blooded, dilated, manifestations of stasis were observed only around the area of adhesive masses. Collagen fibers, which were part of the capsule, that began to form around the fragments of adhesive masses, were thin, more superficially located - picrinophilic, immature. On day 7, a layer of granulation tissue with immature (picrinophilic) and mature (fuchsinophilic) collagen fibers was formed in the treatment zone, infiltration of the treatment zone and surrounding tissues was predominantly lymphocytic, neutrophilic granulocytes were not numerous, and ciliated. Signs of inflammation were moderate. Single fragments of adhesive masses. The epithelial plate was partially restored. The intrinsic plate in the intervention zone was compacted due to the more compact arrangement of the collagen fiber bundles. Blood vessels, especially capillaries and venules, were dilated and full-blooded, there were no manifestations of stasis (Fig. 3).

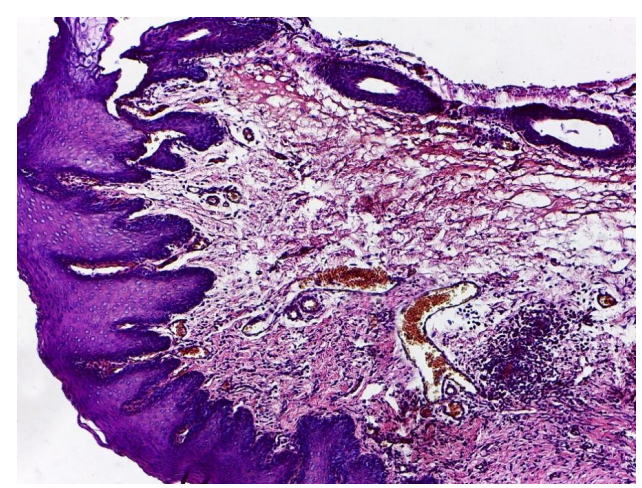

Fig. 3 Rabbit's OM, in 7 days after application of the adhesive composition.

Hematoxylin and eosin staining. Magnification 100

On the 14th day in the treatment area, the epithelial plate was mostly restored, thinned. The own plate sometimes showed signs of edema, the scar area was slightly infiltrated with lymphocytes, the number of neutrophilic granulocytes decreased slightly. Full-blooded blood vessels showed no signs of stasis. On day 21, the collagen fibers in the treatment area (scar) were mature, more compactly located than in intact areas. There are few small macrophages.

As a result of statistical data processing and pairwise comparisons of groups of rabbits on morphometric parameters in order to verify the significance of differences in the levels of morphometric parameters obtained during the study, 48 calculations of the U-test of Mann-Whitney were performed (Table 2).

It was found that in 42 cases ( $87.5 \%$ of the total number of comparisons) there are significant differences in the levels of morphometric parameters between individual groups for each day. 
In four cases, the differences between the groups in terms of GFBC cannot be considered significant, in two cases - in terms of macrophages. This applies more to group No. 2 and No. 3.

Table 2

The results of pairwise assessments of the significance of differences between groups by the Mann-Whitney test on morphometric parameters

\begin{tabular}{|c|c|c|c|c|c|c|c|c|c|}
\hline \multirow{3}{*}{ Indicator } & \multirow{3}{*}{ Group/No. } & \multicolumn{4}{|c|}{ No. 2} & \multicolumn{4}{|c|}{ No. 3} \\
\hline & & \multicolumn{4}{|c|}{ Day } & \multicolumn{4}{|c|}{ Day } \\
\hline & & 3 & 7 & 14 & 21 & 3 & 7 & 14 & 21 \\
\hline A & \multirow{4}{*}{ No. 1} & 1 & 1 & 1 & 1 & 1 & 1 & 1 & 1 \\
\hline B & & 1 & 1 & 1 & 1 & 1 & 1 & 1 & 1 \\
\hline $\mathrm{C}$ & & 1 & 1 & 2 & 0 & 1 & 1 & 1 & 1 \\
\hline $\mathrm{D}$ & & 1 & 2 & 0 & 0 & 1 & 0 & 2 & 1 \\
\hline A & \multirow{4}{*}{ No. 2} & $x$ & $x$ & $x$ & $x$ & 1 & 1 & 1 & 1 \\
\hline B & & $x$ & $x$ & $\times$ & $\times$ & 1 & 1 & 1 & 1 \\
\hline $\mathrm{C}$ & & $x$ & $x$ & $x$ & $\times$ & 0 & 1 & 1 & 1 \\
\hline $\mathrm{D}$ & & $x$ & $x$ & $x$ & $x$ & 0 & 1 & 2 & 1 \\
\hline
\end{tabular}

Note: calculations were performed using the Mann-Whitney U-test; for significance levels $p \leq 0.05$ and $p \leq 0.01$ (according to Gubler E. I., Genkin A. A., 1973) critical values were determined. $\times$-pairwise assessments between the same groups does not make any sense. A - neutrophilic granulocytes; $B$-lymphocytes; $C$ - macrophages; $D-G F B C ; 0$ - the hypothesis is accepted $H_{0}$-differences between groups cannot be considered significant; 1 -the hypothesis is accepted $H_{1}$ - differences between groups can be considered significant ( $p \leq 0.01$ ); 2 - the hypothesis is accepted $H_{1}$-the differences between the groups can be considered significant $(p \leq 0.05)$

The reliability of differences in the levels of morphometric parameters between groups of rabbits on each day is very high, as evidenced by the calculated values of the U-test. In 38 cases, which is $90.5 \%$, the significance level was $p \leq 0.01$, in the other four cases $-p \leq 0.05$.

Analysis of the dynamics of the average levels of neutrophilic granulocytes shows that the greatest value of this morphometric indicator were rabbits of group No. 2. On the $3^{\text {rd }}$ day it was almost nine times higher than the average value in relation to group No. 3 and almost 14 times in relation to group No. 1. In group No. 1 and No. 3, the average levels of neutrophilic granulocytes differed slightly during the three weeks of the experiment and gradually decreased, but the lowest rate was observed in group No. 1. In group No. 2 it also gradually decreased (Fig. 4).

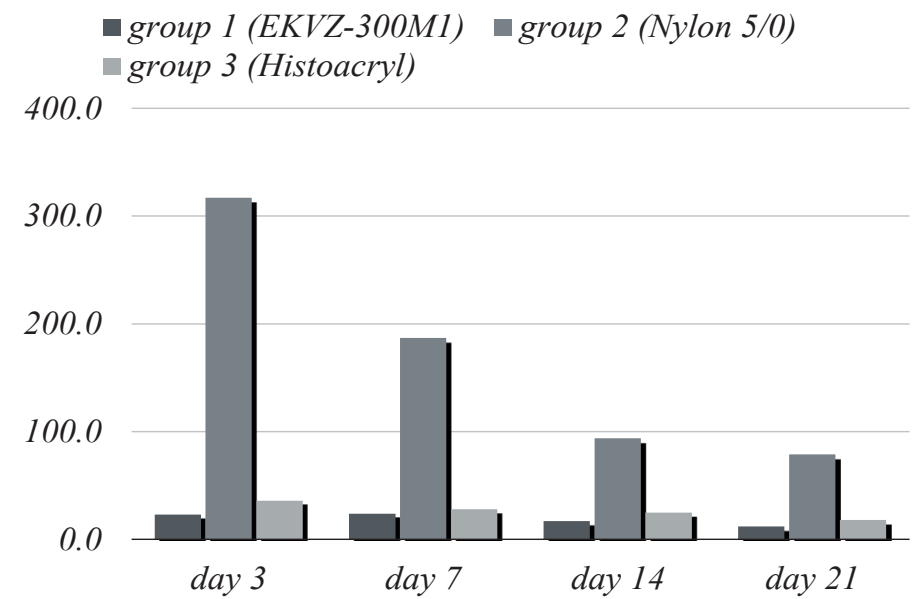

Fig. 4. Dynamics of average values of neutrophilic granulocytes (per $1 \mathrm{~mm}^{2}$ ) 
Indicators of the average level of lymphocytes in group No. 2 and No. 3 differ slightly on each day and tend to decrease.

This indicator reaches the greatest value in group No. 1 for 3 days. It also decreases and, starting from day 14, is almost equal to the indicators in the other two groups, but remains the highest during the whole period of the experiment in comparison with group No. 2 and No. 3 (Fig. 5).

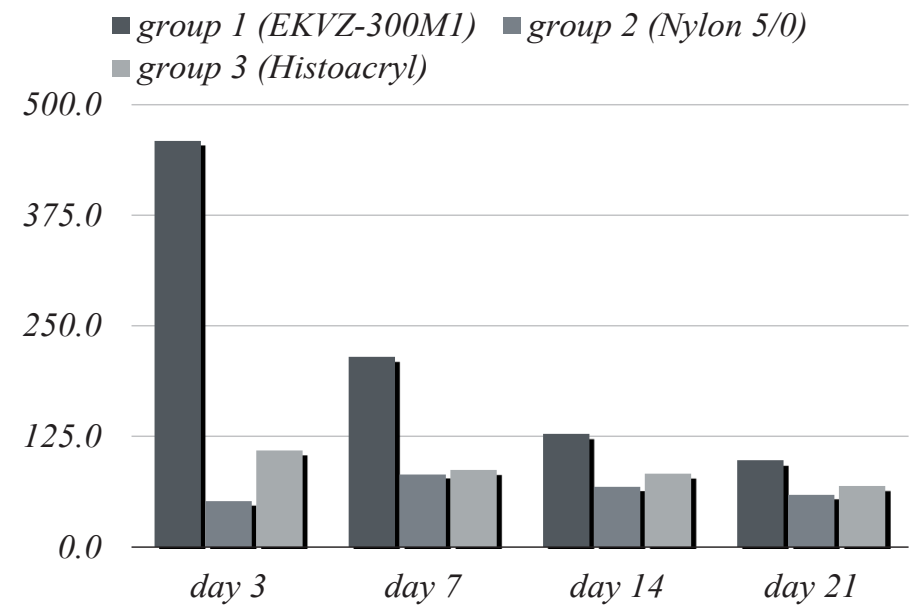

Fig. 5. Dynamics of average values of lymphocytes (per $1 \mathrm{~mm}^{2}$ )

The dynamics of the average level of macrophages is characterized by a sharp increase for day 7 in all groups. It undergoes the greatest changes in group No. 2 . On the $14^{\text {th }}$ day in group No. 2 it decreases, but remains at the highest level. In group No. 1 and No. 3 on the $14^{\text {th }}$ day, the average level of macrophages decreases abruptly and differs slightly in groups, but with a smaller number in group No. 3 (Fig. 6).

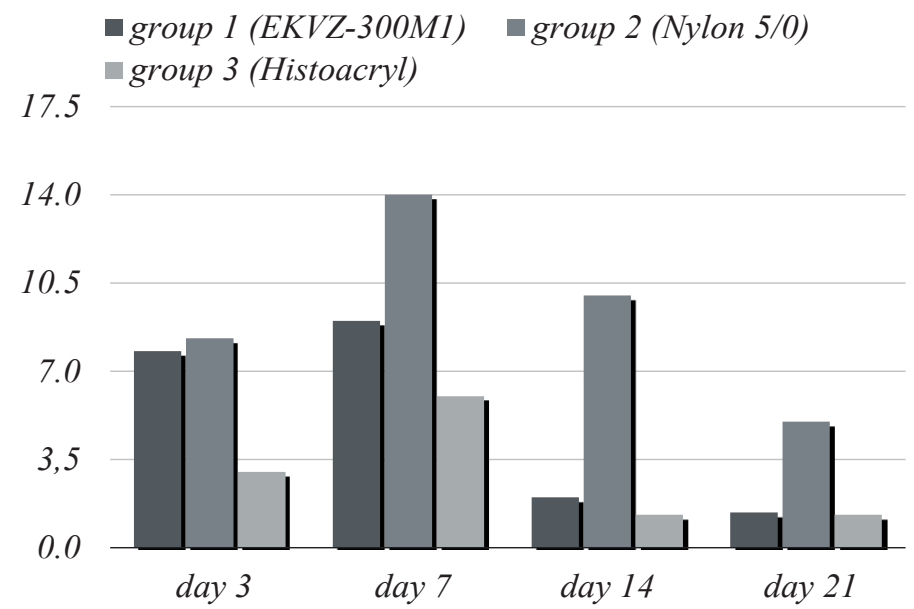

Fig. 6. Dynamics of average values of macrophages (per $1 \mathrm{~mm}^{2}$ )

As for GFBC, these cells are not observed in sight for rabbits of group No. 1. According to the average level of GFBC in group No. 3 it reaches its highest value on day 3. On day 7 decreases twice and is not fixed at all. In group No. 2, this indicator is observed in the field of view from day 7, on day 14 it decreases by two times and remains the same for 21 days (Fig. 7).

The study results show the difference between tissue changes and cellular elements after the use of three methods of connection and hemostasis. According to histological and morphometric data, the best results were observed after the application of high-frequency electric welding and adhesive composition. 


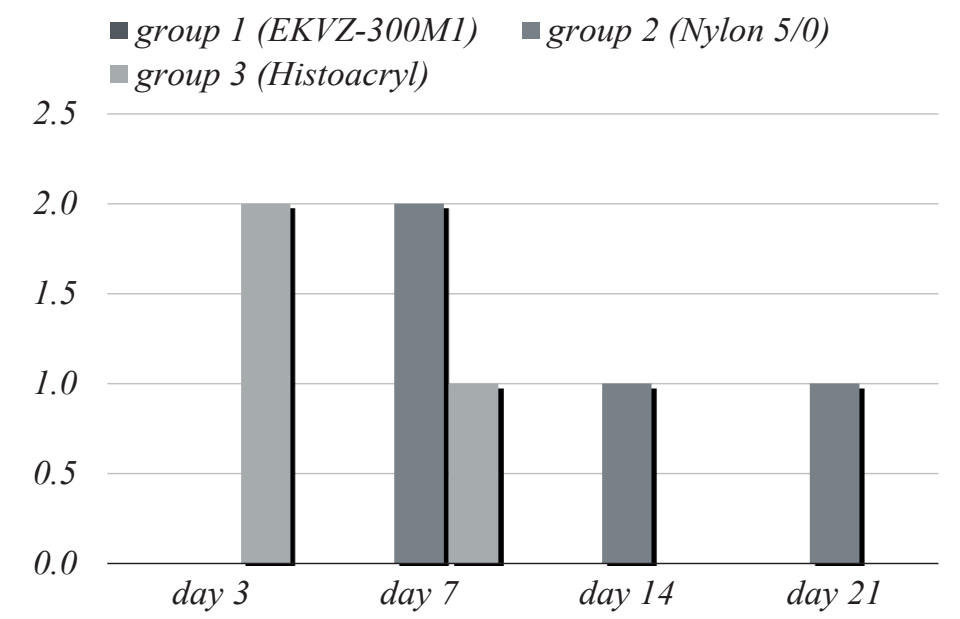

Fig. 7. Dynamics of average values of GFBC in the 8 fields of view

\section{Discussion}

Due to the relentless scientific and technological progress, including in the medical field, there is the necessity to find effective methods of hemostasis and connection of wound edge. In this regard, leading specialists of the E. O. Paton EWI of the National Academy of Sciences of Ukraine (Kyiv) have developed a method of high-frequency electric welding of living soft tissues, which (according to the authors) allows simultaneous hemostasis and wound edges connection. Currently, this method gets rid of the adjective «experimental» and is widely used in surgical otorhinolaryngology [21].

Because of the rare studies and lack of information about the effect of high-frequency electric welding on the oral mucosa [8], the results of histological and morphometric examination were chosen as the evidence base.

Experimental studies in vivo revealed the lowest rates of neutrophilic granulocytes in the group No. 1 (high-frequency electric welding) and No. 3 (adhesive composition) throughout the experiment. A slight difference in the macrophages number per $1 \mathrm{~mm}^{2}$ between the same groups was observed. Rabbits of group No. 3 (nylon 5/0) had the highest rates at all observation times, except lymphocytes per $1 \mathrm{~mm}^{2}$ in comparison with group No. 1 .

Due to the verified and adjusted operating parameters of the device [8], moderate high-frequency electric current and live soft tissues, we observed effective intra-wound hemostasis of the surgical wound and the formation of a «weld», which is confirmed by surgical specialists [22]. In group No. 1 the absence of giant foreign body cells was found at all observation times, but the level of lymphocytes was the highest, compared with group No. 2 and No. 3. This is related to the typical pathological process in the form of aseptic inflammation, faster activation of cellular elements on account of the moderate alterative action of current, the absence of a foreign body in the wound (adhesive masses, filaments). This leads to a faster start of regenerative processes in the treatment area and the beginning of active tissue restructurization in the early stages of observation (the presence of fibroblasts for day 3 ).

Study limitations. The limitation of our study is the research and comparison of only the local effects of physical, mechanical and chemical methods of hemostasis and the connection to the mucous membrane of the oral cavity, taking into account only the dynamics of morphological and morphometric changes, and regenerative qualities of soft tissue in the interventional zone after using each of the methods of hemostasis and connections.

Prospects for further research. It is planned to conduct a clinical study of hemostatic and connecting efficiency after the use of high-frequency electric welding, suturing (nylon 5/0) and the use of tissue adhesive «Histoacryl» by determining the time in each group. Study of patient's pain sensitivity of each group according to the VAS at 1, 3, 5, 7 days after surgery. Assessment of postoperative wound healing after typical surgery on the soft tissues of the jaws, according to the index assessment of REEDA at 1, 3, 5, 7 days, Landry et al. at 3 and 7 days, Wachtel et all. at 3 and 7 days, Hollander et all. at 7 day. Comparison and statistical data processing. Conclusions will be made based on the results of the study. 


\section{Conclusions}

1. The high reliability of differences in the levels of morphometric parameters between groups of rabbits on each of the days, except for the GFBC indicator, as evidenced by the calculated values of the U-Mann-Whitney test. In 38 cases, which is $90.5 \%$, the significance level was $p \leq 0.01$, in 4 cases $-p \leq 0.05$.

2. The lowest value of the average level of neutrophilic granulocytes was observed in rabbits of group No. 1 (electric welding) for each day during the whole experiment compared with rabbits of group No. 2 (nylon 5/0) and No. 3 (adhesive composition). The highest value of the average level of lymphocytes was observed in rabbits of group No. 1, the lowest in rabbits of group No. 2 per day. The lowest value of the average level of macrophages was observed in rabbits of group No. 3 and No. 1.

3. The highest level of GFBC was in group No. 3 already from day 3, twice decreased on day 7, whereas in group No. 2 on the contrary. In rabbits of group No. 1 GFBC were not observed in sight throughout the experiment.

4. Histological and morphometric examination showed less inflammatory-cellular response of tissues, after the use of high-frequency electric welding and adhesive composition in comparison with the use of nylon $5 / 0$.

5. The conducted experimental research indicates a smaller degree of morphological and morphometric changes of oral mucosa after the usage of high-frequency electric welding and adhesive composition, which in turn indicates faster healing of the postoperative wound.

\section{Conflict of interests}

The authors declare that they have no conflicts of interest.

\section{Acknowledgments}

The authors thank the junior medical staff of the Department of Experimental Surgery Shalimov National Institute of Surgery and Transplantology for their assistance in conducting experimental research. Also, we thank the employees of the department No 56 E. O. Paton EWI of the National Academy of Sciences of Ukraine (the department head Khudetskyi I. Yu.) for providing the possibility of using electrosurgical equipment and assistance in the development of specialized bipolar instruments for oral surgery. We are grateful to Babichev Oleksandr for his assistance and processing of the photo material.

\section{References}

[1] Kirsanova, N. M., Lomakin, M. V., Soloshchanskii, I. I. (2018). General and specific cases of hemostasis in reconstructive surgery of oral cavity. Russian Journal of Dentistry, 22 (4), 212-216. doi: http://doi.org/10.18821/1728-2802-2018-22-4-212-216

[2] Kumar S. (2016). Local hemostatic agents in the management of bleeding in oral surgery. Asian Journal of Pharmaceutical and Clinical Research, 9 (3), 35-41.

[3] Chepyshko, S. I., Maksymiv, O. O. (2019). Evaluation of the effectiveness of surgical treatment for dental patients by a comparison to classical surgical method of electric welding of live tissues. Bukovinian Medical Herald, 23 (4 (92)), $161-167$. doi: http://doi.org/10.24061/2413-0737.xxiii.4.92.2019.105

[4] Gay-Escoda, C., Gomez-Santos, L., Sanchez-Torres, A., Herraez-Vilas, J. (2015). Effect of the suture technique on postoperative pain, swelling and trismus after removal of lower third molars: A randomized clinical trial. Medicina Oral Patología Oral y Cirugia Bucal, 20 (3), 372-377. doi: http://doi.org/10.4317/medoral.20307

[5] Vezeau, P. J. (2016). Topical Hemostatic Agents. Oral and Maxillofacial Surgery Clinics of North America, 28 (4), $523-532$. doi: http://doi.org/10.1016/j.coms.2016.06.007

[6] Veleska-Stevkoska, D., Koneski, F. (2018). Haemostasis in Oral Surgery with Blue-Violet Light. Open Access Macedonian Journal of Medical Sciences, 6 (4), 687-691. doi: http://doi.org/10.3889/oamjms.2018.181

[7] Gomathi P., Kavitha J., Rajasekar S., Srinivasan S., Lakshmisree S. (2020). Treatment of Chronic Inflammatory Gingival Enlargement Using Electrosurgery: A Case Report. Journal of Dental and Medical Sciences, 19 (3), 17-20.

[8] Pavlenko, O., Savitskaya, I., Boiko, M. (2020). Dynamics of morphological changes in the recovery of the oral mucosa after the application of the method of high-frequency electric welding. Suchasna stomatolohiya, 2 (101), 44-48. doi: http://doi.org/ $10.33295 / 1992-576 x-2020-2-44$ 
[9] Selvi, F., Çakarer, S., Can, T., Kırlı Topçu, S. İ., Palancığlu, A., Keskin, B. et. al. (2016). Effects of different suture materials on tissue healing. Journal of Istanbul University Faculty of Dentistry, 50 (1), 35-42. doi: http://doi.org/10.17096/jiufd.79438

[10] Dragovic, M., Pejovic, M., Stepic, J., Colic, S., Dozic, B., Dragovic, S. et. al. (2019). Comparison of four different suture materials in respect to oral wound healing, microbial colonization, tissue reaction and clinical features - randomized clinical study. Clinical Oral Investigations, 24 (4), 1527-1541. doi: http://doi.org/10.1007/s00784-019-03034-4

[11] Villa, O., P. Lyngstadaas, S., Monjo, M., Satué, M., J. Rønold, H., Petzold, C., C. Wohlfahrt, J. (2015). Suture materials affect peri-implant bone healing and implant osseointegration. Journal of Oral Science, 57 (3), 219-227. doi: http://doi.org/10.2334/ josnusd.57.219

[12] Oladega, A. A., James, O., Adeyemo, W. L. (2019). Cyanoacrylate tissue adhesive or silk suture for closure of surgical wound following removal of an impacted mandibular third molar: A randomized controlled study. Journal of Cranio-Maxillofacial Surgery, 47 (1), 93-98. doi: http://doi.org/10.1016/j.jcms.2018.10.018

[13] Suthar, P., Shah, S., Waknis, P., Limaye, G., Saha, A., Sathe, P. (2020). Comparing intra-oral wound healing after alveoloplasty using silk sutures and n-butyl-2-cyanoacrylate. Journal of the Korean Association of Oral and Maxillofacial Surgeons, 46 (1), 28-35. doi: http://doi.org/10.5125/jkaoms.2020.46.1.28

[14] Rewainy, M., Osman, S., El-prince, N. (2015). The use of N-Butyl cyanoacrylate adhesive in the closure of mucoperiosteal flap after the surgical extraction of impacted mandibular third molar. Alexandria Dental Journal, 40 (2), $152-159$. doi: http://doi.org/10.21608/adjalexu.2015.59139

[15] Arya, V., Malhotra, V., Dayashankara Rao, J., Sharma, S., Singh, S., Luthra, P. (2016). Evaluating the use of octyl-2cyanoacrylate in unilateral cleft lip repair. National Journal of Maxillofacial Surgery, 7 (2), 153-158. doi: http://doi.org/ 10.4103/0975-5950.201364

[16] Li, W., Xiao, M., Chen, Y., Yang, J., Sun, D., Suo, J., Wang, D. (2019). Serious postoperative complications induced by medical glue: three case reports. BMC Gastroenterology, 19 (1). doi: http://doi.org/10.1186/s12876-019-1142-6

[17] Hagen, S. L., Grey, K. R., Hylwa, S. A. (2016). Allergic contact dermatitis to Dermabond ${ }^{\mathrm{TM}}$ : A case and review of the literature. Wound Medicine, 14, 25-30. doi: http://doi.org/10.1016/j.wndm.2016.07.003

[18] Sagar, P., Prasad, K., Lalitha, R. M., Ranganath, K. (2015). Cyanoacrylate for Intraoral Wound Closure: A Possibility? International Journal of Biomaterials, 2015, 1-6. doi: http://doi.org/10.1155/2015/165428

[19] Smith, A. J., Clutton, R. E., Lilley, E., Hansen, K. E. A., Brattelid, T. (2017). PREPARE: guidelines for planning animal research and testing. Laboratory Animals, 52 (2), 135-141. doi: http://doi.org/10.1177/0023677217724823

[20] Pasupuleti, M., Molahally, S., Salwaji, S. (2016). Ethical guidelines, animal profile, various animal models used in periodontal research with alternatives and future perspectives. Journal of Indian Society of Periodontology, 20 (4), $360-368$. doi: http://doi.org/10.4103/0972-124x.186931

[21] Kosakivska, I. A. (2017). Application of electrothermoadhesion in surgical interventions for the diseases of lymphatic pharyngeal ring in children. Klinicheskaia khirurgiia, 2, 31-33.

[22] Tolstanov, O. K., Rusak, P. S., Danilov, O. A., Lankin, Y. M. et. al. (2018). Electric welding of living soft tissues in paediatric surgery: experience and development prospects. Paediatric Surgery. Ukraine, 1 (58), 28-36. doi: http://doi.org/ $10.15574 /$ ps.2018.58.28

How to cite: Pavlenko, O., Boiko, M., Savitskaya, I., Geylenko, O. (2021). Histotopographic and morphometric characteristics of the oral mucosa postoperative wounds healing, depending on the method of connecting the wound edges. EUREKA: Health Sciences, 3 , 69-78. doi: http://doi.org/10.21303/2504-5679.2021.001845 